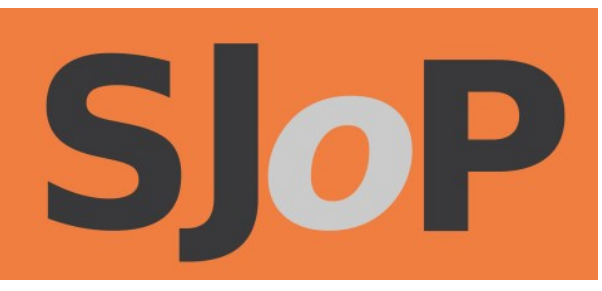

\title{
Performance review: Creating Intimacy, by Shona Mackay
}

\section{JAMES SLIMINGS}

The Scottish Journal of Performance

Volume 6, Issue 1; July 2019

ISSN: 2054-1953 (Print) / ISSN: 2054-1961 (Online)

Publication details: http://www.scottishjournalofperformance.org

To cite this article: Slimings, J., 2019. Performance review: Creating

Intimacy, by Shona Mackay. Scottish Journal of Performance, 6(1): pp.97101.

To link to this article: http://doi.org/10.14439/sjop.2019.0601.08

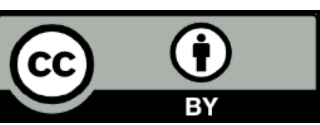

This work is licensed under a Creative Commons Attribution 4.0 International License. See

http://creativecommons.org/licenses/by/4.0/ for details. 


\title{
Performance review: Creating Intimacy, by Shona Mackay
}

\author{
JAMES SLIMINGS
}

DOI: 10.14439/sjop.2019.0601.08

Publication date: 14 July 2019

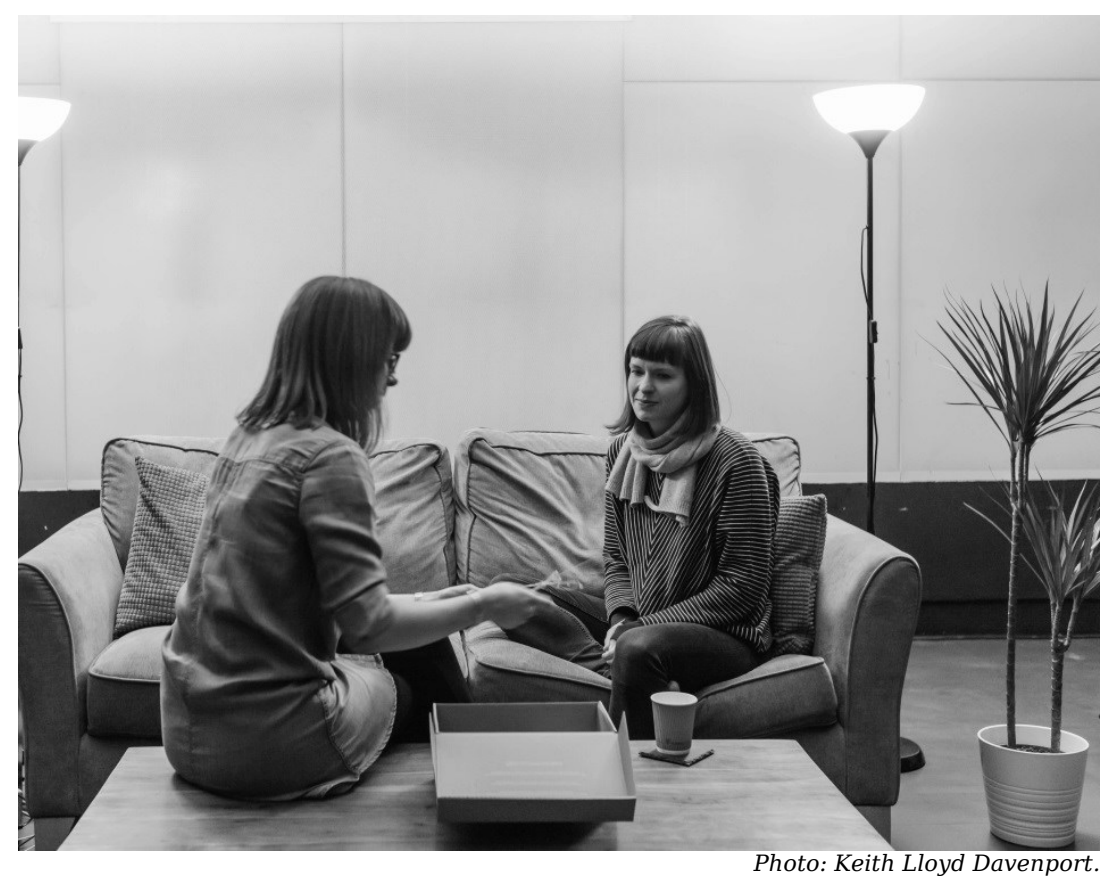

23rd November 2018 CCA, Glasgow

Walking into the familiar surroundings of the foyer of the Centre of Contemporary Arts: Glasgow (CCA) there is a familiar buzz; people sipping lattes and catching up with old friends. The intimacy of these everyday interactions provide the perfect pre-show performance for Shona Mackay's one-to-one experience Creating Intimacy for video, pre-recorded string quartet soundtrack and composer. An usher waiting outside the innocuous sliding door of the cinema took my name and proceeded to sit me down just outside the door with an audio introduction to the work. The headphones cut out the various conversations happening around me that had begun to seem like a performative ritual of its own, and the voice 
of the composer, an integral part of this whole performance, welcomes me to the piece. All this provides a layer of expectation that makes it very clear that this is not a string quartet in the traditional sense. I am invited to take my shoes off and proceed into the cinema.

The vestibule smells reassuringly of incense-I remove my shoes and politely knock on the door to the cinemacome-performance space. The familiarities of this between space, not quite part of the performance, but not far from it, reminded me very much of waiting in the wings before going on stage. I felt as much performer as I did audience, I just didn't have my shoes.

I am greeted by the composer and walk into a space that seems at once familiar and homely, as well as carefully curated and formalized as now being in the performance. The 'set' includes a sofa, rug, and coffee table. In a corner sits a piano and music stand, with a score resting on it. The atmosphere is one of welcome and comfort. I am offered a cup of herbal tea, cinnamon to match the incense, which I accept and I luxuriate in rubbing my toes in the soft pile of the rug.

Mackay is an integral part of this performance. She acts as host to the guest she has brought into a space that exists as her living room in the performance, and which contains furniture from her living room in real life. The introduction and conversation is followed by some joint breathing exercises and Mackay introduces a box of personal trinkets, each with an associated memory, that are provocatively placed on the table in front of us. The conversation is drawn to any similar box that I own and I spend too long talking about brown archive boxes, and table tennis games.

Headphones are placed over my ears and the prerecorded music of the string quartet begins to play. I close my eyes and fully immerse myself in the music. A further stimulation dawns with the opening of my eyes; 
the piece is accompanied by film and now the atmosphere shifts from the delicately composed quartet. In a piece describing intimacy, touch between two humans is one of the more obvious places to start. The film shows the composer herself, and her partner in various embraces, with tender and loving caresses of various parts of their naked forms. While it would have been easy for this to have become sexualized, the film is much gentler and more loving than that, much more akin to Adrien Howells The Pleasure of Being: Washing/Feeding/Holding.

The cinematography perfectly matches the unpretentious score; everything has its place, and I am guided through the narrative of the work. Nothing about the experience is difficult, and the gentle polyphony of the strings mirrors the soft-focus intimacy between the composer and her partner.

The précis to the third and final movement of this three movement string quartet was an exploration of the silent box of memory laden trinkets that had kept vigil throughout the performance. Mackay invited me to share a gesture of intimacy with her during the final movement of the work, the decision regarding this gesture was given to me and I was free to choose a gesture that resonated personally. From the box in front of me, I was drawn to the green, cloth bound book that reminded me of an edition of The Wind in the Willows I own. I did not realize this was a personal diary of the composer and as our gesture we negotiated turning pages, with Mackay occasionally drawing my attention to a piece of text. The music of this movement somewhat underscored what became a conversation of sharing of stories, such as where my father taught me to skim stones, and a trip around Europe by Mackay. This choice to speak during the performance of the music was not something conscious, used to subvert the music, but seemed like the next logical part of our joint experience. Given the impetuous on the participant to guide this moment, it would be possible to miss the third movement altogether. 
As the music drew to a close, I finished my tea, collected an origami memory that Mackay had been making as I listened to her music and left, feeling a great connection to the piece as a whole, and with a desire to hear the score again.

This was an accessible, personal, and extremely well curated work of performance art. It was immersive in every sense (and with every sense) and guided by the presence of the composer. I found the music to be wellcrafted and clear, with punchy counterpoint reminiscent of Tippett's Concerto for Double String Orchestra, but the gentle lyricism of Delius. Undoubtedly this was a piece of film music scored for string quartet, the music syncing to the cinematography deftly, but it was not necessarily the notated score that was the stand out for me.

The 5th instrument in this piece, the composer herself, is the finest part of this immersive performance, and the most memorable part of the experience for me. While it would be easy to dismiss this as a gimmick, the way that each interaction and experience for the audience had been thought through and curated gave the whole score (in its widest possible meaning) a legitimacy as a piece of work that coalesces as a cohesive whole.

Leaving the temporal shelter of the performance space, I could hardly believe that my 30 minute slot was over. Breaking that narrative tension and walking back out in to the real world of Glasgow, I felt that I had not merely listened to, or observed a piece of work, but experienced something else. My origami swan in hand, the intimacy that was created in that performance space was not only an intimacy between composer and work, but also an reconnection with my own self, the memories it evoked were strong, visceral, and sometimes forgotten. Looking at my memento now evokes a different memory, a different feeling, but each of them intimate. 


\section{About the review author}

JAMES SLIMINGS is a final year $\mathrm{PhD}$ student at the Royal Conservatoire of Scotland researching Choral Blend. He has delivered papers at the Conservatoires UK Research Student Conference (Glasgow); Music, Education and Technology Symposium (London); International Symposium on the Histories and Practices of Choral Singing (Lund); and the Scottish Graduate School of Arts and Humanities Doctoral Showcase (Glasgow). This summer he will present at the Oxford University International Conducting Studies Conference in Sydney. He is also a quality assurance reviewer for MUSIQUE and QAA Scotland, and has given talks on Post-Graduate Research studies for the Scottish Funding Council and the Association of European Conservatoires. 